\title{
Mitochondrial therapeutics in Alzheimer's disease and Parkinson's disease
}

\author{
Jake G Hoekstra, Kathleen S Montine, Jing Zhang and Thomas J Montine*
}

\begin{abstract}
In neurons, mitochondria serve a wide variety of processes that are integral to their function and survival. It is, therefore, not surprising that evidence of mitochondrial dysfunction is observed across numerous neurodegenerative diseases. Alzheimer's disease and Parkinson's disease are two such diseases in which aberrant mitochondrial activity is proposed to contribute to pathogenesis. Current therapies for each disease target various mechanisms, but few, if any, directly target improved mitochondrial function. Recent discoveries pertaining to mitochondrial dynamics reveal that regulation of mitochondrial fission and fusion may play a key role in the pathogenesis of these diseases and consequently could be novel future therapeutic targets.
\end{abstract}

\section{Overview of mitochondrial function}

Mitochondria are organelles serving a wide variety of actions critical to cellular function, several of which are of particular importance to neuronal survival. The primary function of mitochondria is to produce energy in the form of ATP via oxidative phosphorylation, in which electrons are transported down the electron transport chain (ETC) while generating a proton gradient. This gradient drives ATP synthase [1]. Mitochondrial function is particularly important to the central nervous system (CNS) since the CNS uses 20\% of the body's resting metabolic energy, $95 \%$ of which comes in the form of ATP [1]. Neuronal ATP is essential to the function of the $\mathrm{Na}^{+} / \mathrm{K}^{+}$and $\mathrm{Ca}^{2+}$ ATPases that maintain ion gradients $[1,2]$. Similarly, mitochondria play a prominent role in $\mathrm{Ca}^{2+}$ buffering by sequestering $\mathrm{Ca}^{2+}$ using ion transporters [1-3]. These actions of mitochondria are especially important to neurotransmission as well as synapse

*Correspondence: tmontine@uw.edu

Department of Pathology, University of Washington, 325 9th Avenue, Seattle, WA 98104, USA formation and remodeling [3-5]. However, critical roles for mitochondria go beyond ATP production since mitochondria also control cell signaling pathways and cell survival via apoptosis regulation [6]. Mitochondria are now also understood to be dynamic structures that undergo fission and fusion, and the relationships between mitochondrial dynamics and other 'classical' functions are a matter of intense investigation. For these reasons, mitochondria are commonly implicated in neurodegenerative diseases, including Alzheimer's disease (AD) and Parkinson's disease (PD).

Several neurodegenerative diseases show alterations in mitochondrial DNA (mtDNA) and genes that encode for mitochondria respiratory chain subunits [7]. Similarly, dysfunction of enzymes involved in mitochondrial respiration has been reported in neurodegenerative diseases $[7,8]$. Such deficits may lead to generation of excessive reactive oxygen species (ROS) and oxidative damage, clearly implicated in several neurodegenerative diseases, or to depletion of ATP $[7,8]$. Besides damaging tissues directly, ROS are thought to react with the nitric oxide (NO) produced by activated microglia, forming reactive nitrogen species (RNS) [7]. More recently, it has been demonstrated that mitochondrial dynamics likely plays a key role in $\mathrm{AD}$ and $\mathrm{PD}$ as proteins that regulate mitochondrial fission and fusion are altered in some neurodegenerative diseases $[3,8]$. Given the proposed role of mitochondrial dysfunction in $\mathrm{AD}$ and $\mathrm{PD}$, restoration of mitochondrial function is a focus of therapeutic development.

This review will concentrate on mitochondrial involvement in $\mathrm{AD}$ and PD and emphasize current therapeutics that may directly or indirectly target mitochondria function. Potential roles of mitochondrial fission and fusion, at present a major area of active research, in $\mathrm{AD}$ and PD treatment also will be addressed.

\section{Alzheimer's disease}

\subsection{Clinical presentation and pathology}

$\mathrm{AD}$ is the most common neurodegenerative disease, contributing up to $70 \%$ of all cases of dementia, and has an exponentially increasing prevalence after the age of 65 [9]. Both common late-onset sporadic and rare autosomal 
dominant forms exist [10]. Biomarkers in cerebrospinal fluid or structural and functional neuroimaging are being used to assist in clinical classification of AD [11]. Pathologically, $\mathrm{AD}$ is characterized by the presence of neuritic plaques and neurofibrillary tangles, composed primarily of amyloid-beta $(A \beta)$ and abnormal tau (respectively), which are found predominantly in cerebral cortex and other medial temporal lobe structures [9]. It is worth noting that, to date, most of the effective $\mathrm{AD}$ biomarkers are related to $A \beta$ or tau species $[11,12]$. The earliest pathologic event occurring in $\mathrm{AD}$ is thought to be synapse loss, as several changes in proteins related to synaptic vesicles and membranes have been observed in $\mathrm{AD}$ brains $[9,13]$. It is hypothesized that soluble $\mathrm{A} \beta$ oligomers cause synaptic and neuronal dysfunctions that then lead to potentially interconnected processes of excitotoxicity, neuroinflammation, oxidative damage, insoluble protein accumulation, and neurodegeneration $[9,14]$.

\subsection{Mitochondrial involvement in Alzheimer's disease}

Mitochondrial abnormalities have been associated with AD. Several enzymes involved in the Krebs cycle and ETC, including pyruvate dehydrogenase complex, ketoglutarate dehydrogenase complex, and cytochrome oxidase, are altered in the brains, platelets, and peripheral cells of AD patients [15-18]. Isolated mitochondria from $\mathrm{AD}$ patients also show decreased complex IV activity as well as elevated hydrogen peroxide production [19]. Indeed, oxidative damage to DNA, proteins, and lipids is elevated in AD patients compared with controls [20-22]. $A \beta$ has also been linked to mitochondrial dysfunction in various studies. $A \beta$, especially the peptide that is 42 amino acids long, is toxic to cells in vitro [23] and decreases ETC complex IV activity [24]. A $\beta$ or the $A \beta$ precursor protein (APP) associates with mitochondria in the brains of $\mathrm{AD}$ patients, particularly with the translocase of the outer mitochondrial membrane (TOMM) 40 and the translocase of the inner mitochondrial membrane (TIMM) 23, suggesting possible mitochondrial translocation $[19,25]$. When a mutant form of human APP is overexpressed in mice, $A \beta$ accumulates in mitochondria and, compared with controls, decreases $\mathrm{Ca}^{2+}$ buffering capacity, complex IV activity, and ATP levels and increases ROS production [26]. Two recent studies have found that $A \beta$ induces abnormal mitochondrial transport within axons $[27,28]$. Therefore, elevated A $\beta$ might contribute to mitochondrial dysfunction, ROS production, and stress to neurons in $\mathrm{AD}$. An alternative hypothesis asserts that, in sporadic $\mathrm{AD}$, mitochondrial function declines beyond a threshold level to activate a pathway yielding the pathologic hallmarks of AD, specifically overproduction of $A \beta$ [29]. This would exacerbate mitochondrial dysfunction, leading to a reinforcing destructive cycle [29]. Key findings that support this hypothesis come from the use of cybrids (that is, cells with mitochondria derived from another cell). For example, mitochondria from fibroblasts and platelets of $\mathrm{AD}$ patients show decreased complex IV activity, a feature that remains consistent when cybrids are cultured over time, leading to elevated $A \beta$ production and deposits $[29,30]$.

\subsection{Therapeutics and treatment}

Current therapies for $\mathrm{AD}$ do not directly target mitochondria but may act through various mechanisms that can affect mitochondria (Table 1). One such mechanism is regulation of neuroinflammation [7]. When activated, microglia produce $\mathrm{NO}$, which can interact with ROS (produced by mitochondria as a normal product of ETC activity) to generate RNS [7]. ROS and RNS can damage mitochondria as well as other organelles, leading to decreased ETC function, further ROS production, and decreased ATP production, resulting in neuron death [7]. Cholinesterase inhibitors such as donepezil, rivastigmine, and galantamine, which are approved by the US Food and Drug Administration (FDA) for AD treatment, may function through this manner as their use decreases markers of inflammation and improve $\mathrm{AD}$ symptoms $[31,32]$. Nonsteroidal anti-inflammatory drugs (NSAIDs) may decrease inflammation in a similar manner, but results from observational studies and clinical trials have not been consistent [31-33]. Another mechanism is by decreasing $\mathrm{Ca}^{2+}$ entry into neurons, as excessive intracellular $\mathrm{Ca}^{2+}$ can cause mitochondrial dysfunction, resulting in ATP depletion and excessive ROS generation [34]. Blocking $\mathrm{Ca}^{2+}$ influx decreases the amount of intracellular $\mathrm{Ca}^{2+}$ present in neurons, and this would decrease ROS generation by mitochondria. N-methyl-D-aspartate (NMDA) receptor antagonists (also FDA-approved for $\mathrm{AD}$ treatment) that suppress $\mathrm{Ca}^{2+}$ channel activity have been used with some success in treating $\mathrm{AD}[31,32]$. A recent strategy that may affect mitochondria is decreasing $A \beta$ load, and this may be achieved by decreasing $A \beta$ production or enhancing its clearance $[31,35]$. Excessive levels of $\mathrm{A} \beta$ may be taken up by mitochondria, causing decreased complex IV activity, ATP production, and $\mathrm{Ca}^{2+}$ buffering, resulting in excessive ROS production and neuron death [19,23-26]. A $\beta$ immunotherapy is an avenue being investigated to treat $A D$ by reducing $A \beta$ levels and has yielded some promising results [35]. An $A \beta$ vaccine consisting of a synthetic $A \beta$ peptide and an immune response booster was developed and tested in humans, but its trial was halted because of the development of aseptic meningoencephaitis and leukoencephalopathy (reviewed in [35]). Some follow-up studies indicated changes in biomarkers associated with $\mathrm{AD}$, decreased $A \beta$ load in plaques, and (in those who produced anti- $A \beta$ 
Table 1. Current treatments for Alzheimer's disease

\begin{tabular}{lll}
\hline Therapy & Results & Mitochondrial involvement? \\
\hline Cholinesterase inhibitors & $\begin{array}{l}\text { Improves AD symptoms and decreases markers of } \\
\text { inflammation } \\
\text { NMDA receptor antagonists }\end{array}$ & $\begin{array}{l}\text { May decrease nitric oxide produced, leading to decreased } \\
\text { RNS and ROS }\end{array}$ \\
Enhanced clearance of A & May improve cognition & $\begin{array}{l}\text { May decrease amount of ROS produced due to excessive } \\
\text { intracellular Ca }{ }^{2+}\end{array}$ \\
NSAIDs & No consistent results & $\begin{array}{l}\text { May decrease A A-induced mitochondrial dysfunction and } \\
\text { ROS generation }\end{array}$ \\
Antioxidants & No consistent results & May reduce inflammation and ROS \\
Herbal/Natural products & No consistent results & Can reduce ROS
\end{tabular}

$A \beta$, amyloid-beta; $A D$, Alzheimer's disease; NMDA, N-methyl-D-aspartate; NSAID, nonsteroidal anti-inflammatory drug; RNS, reactive nitrogen species; ROS, reactive oxygen species.

antibodies) decreased rate of cognitive decline [36]; however, others reported that clearance did not prevent progressive neurodegeneration [37]. Current trials that are in various phases and that use passive immunization against $A \beta$ (that is, anti-A $\beta$ antibodies) are being evaluated, but further studies are clearly needed [35]. A $\beta$ binding alcohol dehydrogenase (ABAD), an enzyme present in neuronal mitochondria, has been shown to coimmunoprecipitate and colocalize with $A \beta$ in human tissue, with increased precipitation in AD patients [38]. Data from mouse models of AD support inhibiting $A \beta$ ABAD interaction as a possible therapeutic strategy for AD [38,39]. Other treatments such as antioxidants, vitamins, statins, natural products, and hormone therapy have been studied but do not give consistent results [31-33].

\section{Parkinson's disease}

\subsection{Clinical presentation and pathology}

$\mathrm{PD}$ is a progressive neurodegenerative disease with an average age of onset of between 55 and 60 years of age and a $2 \%$ lifetime risk [40]. As with AD cases, a small fraction of PD cases (5\% to 10\%) are due to autosomal dominant or recessive forms of disease, whereas the majority of PD cases are sporadic [40]. PD is diagnosed clinically by a constellation of motor symptoms, including resting tremor, rigidity, postural instability, and slowness of movement (bradykinesia) [40,41]. The most prominent changes in PD are loss of dopamine (DA)-producing neurons that project from the substantia nigra pars compacta $(\mathrm{SNpc})$ to the striatum $[40,41]$ and accumulation of eosinophilic intraneuronal protein inclusions called Lewy bodies $[34,40,41]$. Lewy bodies are composed primarily of $\alpha$-synuclein, parkin, ubiquitin, and neurofilaments $[34,41]$. Currently, it is thought that one of the proximal events leading to DA neuron death is the formation of $\alpha$-synuclein fibrils from misfolded $\alpha$-synuclein [34]. These fibrils can continue to aggregate misfolded proteins, leading to the formation of larger inclusions with the eventual formation of Lewy bodies and ultimately neuron death $[34,41]$.

\subsection{Mitochondrial involvement in Parkinson's disease}

Mitochondrial dysfunction has been repeatedly associated with PD. Complex I of the ETC is decreased in the $\mathrm{SNpc}$ of PD patients when compared with controls, leading to excessive ROS formation [42]. Oxidative damage to lipids, proteins, and nucleic acids is also elevated in PD brain tissue [43-45]. Toxicants recapitulating most aspects of human PD also implicate mitochondrial dysfunction in PD pathogenesis, particularly through complex I inhibition. These toxicants include 1-methyl-4-phenyl-1,2,3,6-tetrahydropyridine (MPTP) and rotenone [46]. MPTP was discovered when a drug abuser who synthesized and injected himself with MPTPcontaminated meperidine analog presented with parkinsonism; this patient later showed damage to the DA system in the SNpc at autopsy [47]. Other drug abusers subsequently presented with clinical symptoms of PD due to MPTP exposure [46]. MPTP is metabolized to 1-methy-4-penylpyridium $\left(\mathrm{MPP}^{+}\right)$, which enters $\mathrm{DA}$ neurons via the DA transporter. $\mathrm{MPP}^{+}$binds to and inhibits complex I of the ETC, leading to DA neuron death and PD symptoms [46]. Rotenone also acts by inhibiting complex I. Although rotenone is highly lipophilic and can cross the plasma membrane, it causes selective DA neuron degeneration with elevated oxidative stress, indicating that DA neurons may be particularly susceptible to mitochondrial dysfunction [48].

Studies on two genes that are mutated in inherited forms of PD, PINK1, and parkin further implicate mitochondria in PD. In Drosophila, ablation of either gene causes flight muscle degeneration, and mitochondria appear enlarged and swollen with fragmented christae [49-51]. Whereas parkin expression in a PINK1 knockout reverses this phenotype, PINK1 expression in a parkin knockout does not, indicating that parkin acts downstream of PINK1 to affect mitochondria [49-51]. 
Table 2. Current treatments for Parkinson's disease

\begin{tabular}{|c|c|c|}
\hline Therapy & Results & Mitochondrial involvement? \\
\hline Levadopa and DA agonists & Improves PD symptoms & $\begin{array}{l}\text { May improve mitochondrial function in neurons by restoring } \\
\text { nigrostriatal signaling }\end{array}$ \\
\hline MAO-B inhibitors & Blocks oxidative deamination & $\begin{array}{l}\text { May improve mitochondrial function in neurons targeted by DA and } \\
\text { may decrease ROS produced by mitochondria }\end{array}$ \\
\hline COMT inhibitors & Blocks catechol metabolism & $\begin{array}{l}\text { May improve mitochondrial function in neurons by restoring } \\
\text { nigrostriatal signaling }\end{array}$ \\
\hline Anticholinergic drugs & Most effective in alleviating tremor and rigidity & $\begin{array}{l}\text { May improve mitochondrial function in striatal neurons by balancing } \\
\text { the DA and acetylcholine }\end{array}$ \\
\hline NMDA receptor antagonists & Can suppress dyskinesia & $\begin{array}{l}\text { May decrease amount of ROS produced due to excessive intracellular } \\
\mathrm{Ca}^{2+}\end{array}$ \\
\hline Coenzyme $\mathrm{Q}_{10}$ & $\begin{array}{l}\text { Less disability develops in patients given } \\
\text { Coenzyme } Q_{10} \text { compared with placebo in } \\
\text { one study [59] }\end{array}$ & $\begin{array}{l}\text { May increase electron flow in electron transport chain and decrease } \\
\text { ROS production }\end{array}$ \\
\hline Creatine & $\begin{array}{l}\text { Not rejected as futile in a phase II futility } \\
\text { clinical trial [58] }\end{array}$ & $\begin{array}{l}\text { May increase high-energy phosphate pool and decrease ROS } \\
\text { production }\end{array}$ \\
\hline
\end{tabular}

COMT, catechol-O-methyltransferase; DA, dopamine; MAO-B, monoamine oxidase B; NMDA, N-methyl-D-aspartate; PD, Parkinson's disease; ROS, reactive oxygen species.

DA neuron degeneration in PINK1- and parkin-deficient Drosophila also has been observed [51,52] along with sensitivity to compounds that model PD and generate ROS [49]. One hypothesis is that loss of these PD-related genes that help regulate mitochondrial function leads to increased sensitivity to neurotoxic insults and DA neuron death.

\subsection{Therapeutics and treatment}

As with $\mathrm{AD}$, a majority of current PD treatments (Table 2) do not target the mitochondria directly, although mitochondrial protection is more common in PD than $\mathrm{AD}$. The current gold standard to restore DA signaling is the DA precursor levodopa (L-DOPA), which crosses the blood brain barrier, combined with a peripheral decarboxylase inhibitor such as carbidopa, which minimizes the gastrointestinal and cardiovascular side effects of DA [53,54]. Treatment may also include a selective inhibitor of monoamine oxidase $\mathrm{B}$ (MAO-B) or catechol-O-methyltransferase (COMT) to decrease DA metabolism [53,54]. DA agonists also have been used but appear less effective than L-DOPA [53,54]. Unfortunately, the effectiveness of L-DOPA therapy often is limited and can be associated with debilitating side effects [54]. LDOPA has been hypothesized to enhance neurodegeneration [54] since DA metabolism by MAO-B generates ROS [55]. In theory, this oxidative stress would cause mitochondrial dysfunction and further ROS production. MAO-B inhibitors may decrease the amount of oxidative damage potentially caused by DA metabolism [53,54]; however, data from some clinical investigations do not support this hypothesis [56]. Regulation of $\mathrm{Ca}^{2+}$ influx shows a slight effect in alleviating dyskinesia in $\mathrm{PD}$ patients $[53,54]$. While regulation of intracellular $\mathrm{Ca}^{2+}$ to prevent ROS production is a potential therapeutic target in PD, NMDA receptor antagonists that block $\mathrm{Ca}^{2+}$ entry have shown minimal benefits in treating PD [53,54]. A more promising strategy may be to supplement mitochondria with molecules that improve their function. In this case, not only would ATP production improve, but ROS production by mitochondria might be decreased [53,54,57-59]. Coenzyme $Q_{10}$ and creatine both may act through such a mechanism, with Coenzyme $\mathrm{Q}_{10}$ improving electron flow and creatine improving high-energy phosphate reservoirs [53,54,57-59]. Any approach that suppresses ROS production might also impact Lewy body formation since ROS can modify $\alpha$-synuclein, increasing its tendency to aggregate and possibly form Lewy bodies $[34,40]$.

\section{Mitochondrial dynamics: new direction of mitochondrial research and potential therapeutics}

Although mitochondrial dysfunction is extensively associated with $\mathrm{AD}$ and $\mathrm{PD}$, direct effective mitochondrial therapy is very limited. A new area of mitochondrial research, known as mitochondrial dynamics, may provide new opportunities for mitochondrial therapies in $\mathrm{AD}$ and $\mathrm{PD}$. Accumulating evidence suggests that mitochondrial morphology and transport can be regulated by fission and fusion, with fusion regulated primarily by mitofusins (Mfn) 1 and 2 and optic atrophy 1 (OPA1) and fission regulated primarily by Fis1 and dynamin-related protein 1 (Drp1) [60]. Several observations support the involvement of mitochondrial dynamics in neurodegeneration. Mutations in Mfn2 lead to Charcot-Marie-Tooth disease and peripheral neuropathy, and mutations in OPA1 lead to autosomal dominant optic atrophy and loss of optic nerve fibers 


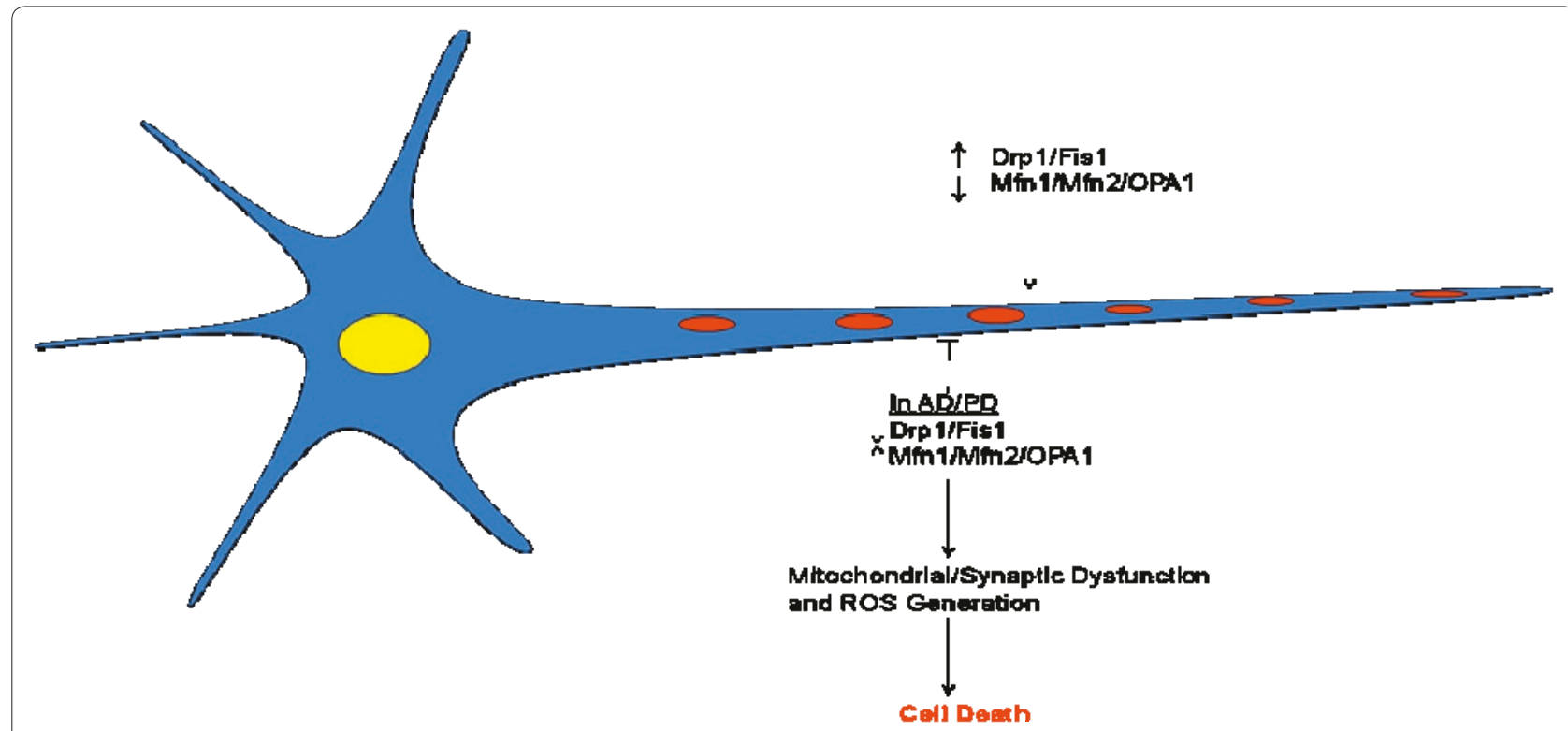

Figure 1. Synaptic function is dependent on proper trafficking of mitochondria to synapses. Mitochondrial trafficking down a neurite to a synapse can be promoted by increased fission (Drp1 or Fis 1) or decreased fusion (Mfn1/2 or OPA1). Alterations in the levels of these proteins can lead to synaptic and mitochondrial dysfunction, neurodegeneration, and AD/PD pathogenesis. AD, Alzheimer's disease; Drp1, dynamin-related protein 1; Mfn, mitofusin; OPA1, optic atrophy 1; PD, Parkinson's disease.

$[3,8,60]$. More recently, Drp1, Mfn1, Mfn2, and OPA1 levels were shown to be decreased in brain tissue from AD patients whereas Fis1 levels were increased [5]. When these changes were mimicked in primary neurons using RNAi (RNA interference) or gene overexpression, mitochondria were decreased in neurites and dendritic spines, indicating that such changes may play a role in AD [5]. This study also showed that Drp1 overexpression in primary cultures protected neurons against neurotoxic insult, suggesting that increased fusion may be a neuroprotective strategy [5]. In a separate study, Drp1 was genetically ablated in Drosophila with a resulting loss of synaptic mitochondria, perhaps due to defects in axonal transport [61], an aspect of neuronal function affected in neurodegenerative diseases [62]. Using the neuromuscular junction (NMJ) to study synaptic actions of Drp1, the same group observed defects in $\mathrm{Ca}^{2+}$ buffering and neurotransmission during prolonged stimulation of the NMJ [61]. In a study of PINK1 and parkin in Drosophila, mitochondrial size and shape and muscle degeneration phenotypes observed in knockout Drosophila were reversed when Drp1 was overexpressed or Mfn2 or OPA1 function was decreased, again showing that increased fission or decreased fusion may be protective [50]. Although this is a relatively recent area of research, these results suggest that loss of fission or increased fusion could play a role in $\mathrm{AD}$ or PD. A proposed connection of mitochondrial fission and fusion to $\mathrm{AD}$ and $\mathrm{PD}$ is diagrammed in Figure 1. Mitochondrial dynamics also may alter mitophagy (elimination of dysfunctional mitochondria) [63], a topic beyond the scope of this review. Regulating mitochondrial dynamics is a new and emerging topic that may provide new targets for therapy.

\section{Conclusions}

Mitochondrial dysfunction is a feature of AD and PD. Mitochondria can affect neuronal function not only through ATP production but also through regulation of ion homeostasis (especially $\mathrm{Ca}^{2+}$ ), synapse function, ROS generation, cell signaling, and survival. Current therapies for AD and PD might influence mitochondrial function indirectly, but few specifically target mitochondrial function. Regulating mitochondrial dynamics might provide new targets for mitochondria-directed therapy in $\mathrm{AD}$ and $\mathrm{PD}$.

\section{Abbreviations}

$A \beta$, amyloid-beta; $A B A D$, amyloid-beta-binding alcohol dehydrogenase; $A D$, Alzheimer's disease; APP, amyloid-beta precursor protein; CNS, central nervous system; DA, dopamine; Drp1, dynamin-related protein 1; ETC, electron transport chain; FDA, US Food and Drug Administration; L-DOPA, levodopa; MAO-B, monoamine oxidase B; Mfn, mitofusin; MPP, 1-methy-4-penylpyridium; MPTP, 1-methyl-4-phenyl-1,2,3,6-tetrahydropyridine; NMDA, N-methylD-aspartate; NMJ, neuromuscular junction; NO, nitric oxide; OPA1, optic atrophy 1; PD, Parkinson's disease; RNS, reactive nitrogen species; ROS, reactive oxygen species; SNpc, substantia nigra pars compacta.

\section{Competing interests}

The authors declare that they have no competing interests.

\section{Authors' contributions}

All authors participated in planning, writing, and revising this manuscript and read and approved the final version. 


\section{Acknowledgments}

This review was supported by National Institutes of Health grants ES004696, NS057567, AG033398, NS062684, ES016873, ES007032, ES016754, and AG05136, the C-M Shaw Endowment, and the Nancy and Buster Alvord Endowment.

Published: 29 June 2011

\section{References}

1. Mironov SL: Complexity of mitochondrial dynamics in neurons and its control by ADP produced during synaptic activity. Int J Biochem Cell Biol 2009, 41:2005-2014

2. Kann O, Kovács R: Mitochondria and neuronal activity. Am J Physiol Cell Physiol 2007, 292:C641-657

3. Ly C, Verstreken P: Mitochondria at the synapse. Neuroscientist 2006, 12:291-299.

4. Li Z, Okamoto K, Hayashi Y, Sheng M: The importance of dendritic mitochondria in the morphogenesis and plasticity of spines and synapses. Cell 2004, 119:873-887

5. Wang X, Su B, Lee HG, Li X, Perry G, Smith MA, Zhu X: Impaired balance of mitochondrial fission and fusion in Alzheimer's disease. J Neurosci 2009, 29:9090-9103.

6. McBride HM, Neuspiel M, Wasiak S: Mitochondria: more than just a powerhouse. Curr Biol 2006, 16:R551-560.

7. Di Filippo M, Chiasserini D, Tozzi A, Picconi B, Calabresi P: Mitochondria and the link between neuroinflammation and neurodegeneration. J Alzheimers Dis 2010, 20 Suppl 2:S369-379.

8. Morais VA, De Strooper B: Mitochondria dysfunction and neurodegenerative disorders: cause or consequence. J Alzheimers Dis 2010, 20 Suppl 2:S255-263

9. Castellani RJ, Rolston RK, Smith MA: Alzheimer disease. Dis Mon 2010, $56: 484-546$

10. Swerdlow RH, Parks JK, Miller SW, Tuttle JB, Trimmer PA, Sheehan JP, Bennett JP Jr., Davis RE, Parker WD Jr.: Origin and functional consequences of the complex I defect in Parkinson's disease. Ann Neurol 1996, 40:663-671.

11. Hampel H, Frank R, Broich K, Teipel SJ, Katz RG, Hardy J, Herholz K, Bokde AL, Jessen F, Hoessler YC, Sanhai WR, Zetterberg H, Woodcock J, Blennow K: Biomarkers for Alzheimer's disease: academic, industry and regulatory perspectives. Nat Rev Drug Discov 2010, 9:560-574.

12. Formichi P, Battisti C, Radi E, Federico A: Cerebrospinal fluid tau, A beta, and phosphorylated tau protein for the diagnosis of Alzheimer's disease. J Cell Physiol 2006, 208:39-46.

13. Arendt T: Synaptic degeneration in Alzheimer's disease. Acta Neuropathol 2009, 118:167-179.

14. Walsh DM, Selkoe DJ: A beta oligomers - a decade of discovery. J Neurochem 2007, 101:1172-1184.

15. Sorbi S, Bird ED, Blass JP: Decreased pyruvate dehydrogenase complex activity in Huntington and Alzheimer brain. Ann Neurol 1983, 13:72-78.

16. Gibson GE, Sheu KF, Blass JP, Baker A, Carlson KC, Harding B, Perrino P. Reduced activities of thiamine-dependent enzymes in the brains and peripheral tissues of patients with Alzheimer's disease. Arch Neurol 1988, 45:836-840

17. Kish SJ, Bergeron C, Rajput A, Dozic S, Mastrogiacomo F, Chang LJ, Wilson JM, DiStefano LM, Nobrega JN: Brain cytochrome oxidase in Alzheimer's disease. J Neurochem 1992, 59:776-779.

18. Parker WD Jr., Mahr NJ, Filley CM, Parks JK, Hughes D, Young DA, Cullum CM: Reduced platelet cytochrome c oxidase activity in Alzheimer's disease. Neurology 1994, 44:1086-1090.

19. Devi L, Prabhu BM, Galati DF, Avadhani NG, Anandatheerthavarada HK: Accumulation of amyloid precursor protein in the mitochondrial import channels of human Alzheimer's disease brain is associated with mitochondrial dysfunction. J Neurosci 2006, 26:9057-9068.

20. Wang J, Xiong S, Xie C, Markesbery WR, Lovell MA: Increased oxidative damage in nuclear and mitochondrial DNA in Alzheimer's disease. J Neurochem 2005, 93:953-962.

21. Smith CD, Carney JM, Starke-Reed PE, Oliver CN, Stadtman ER, Floyd RA Markesbery WR: Excess brain protein oxidation and enzyme dysfunction in normal aging and in Alzheimer disease. Proc Natl Acad Sci U S A 1991 , 88:10540-10543.

22. Lovell MA, Ehmann WD, Butler SM, Markesbery WR: Elevated thiobarbituric acid-reactive substances and antioxidant enzyme activity in the brain in
Alzheimer's disease. Neurology 1995, 45:1594-1601.

23. Cardoso SM, Santana I, Swerdlow RH, Oliveira CR: Mitochondria dysfunction of Alzheimer's disease cybrids enhances Abeta toxicity. J Neurochem 2004 89:1417-1426.

24. Crouch PJ, Blake R, Duce JA, Ciccotosto GD, Li QX, Barnham KJ, Curtain CC, Cherny RA, Cappai R, Dyrks T, Masters CL, Trounce IA: Copper-dependent inhibition of human cytochrome $c$ oxidase by a dimeric conformer of amyloid-beta1-42. J Neurosci 2005, 25:672-679.

25. Hansson Petersen CA, Alikhani N, Behbahani H, Wiehager B, Pavlov PF, Alafuzoff I, Leinonen V, Ito A, Winblad B, Glaser E, Ankarcrona M: The amyloid beta-peptide is imported into mitochondria via the TOM import machinery and localized to mitochondrial cristae. Proc Natl Acad Sci U S A 2008, 105:13145-13150.

26. Du H, Guo L, Fang F, Chen D, Sosunov AA, McKhann GM, Yan Y, Wang C, Zhang H, Molkentin JD, Gunn-Moore FJ, Vonsattel JP, Arancio O, Chen JX, Yan SD: Cyclophilin D deficiency attenuates mitochondrial and neuronal perturbation and ameliorates learning and memory in Alzheimer's disease. Nat Med 2008, 14:1097-1105.

27. Vossel KA, Zhang K, Brodbeck J, Daub AC, Sharma P, Finkbeiner S, Cui B, Mucke $L$ : Tau reduction prevents Abeta-induced defects in axonal transport. Science 2010, 330:198.

28. Du H, Guo L, Yan S, Sosunov AA, McKhann GM, Yan SS: Early deficits in synaptic mitochondria in an Alzheimer's disease mouse model. Proc Natl Acad Sci U S A 2010, 107:18670-18675.

29. Swerdlow $\mathrm{RH}, \mathrm{Khan} \mathrm{SM}$ : The Alzheimer's disease mitochondrial cascade hypothesis: an update. Exp Neurol 2009, 218:308-315.

30. Khan SM, Cassarino DS, Abramova NN, Keeney PM, Borland MK, Trimmer PA Krebs CT, Bennett JC, Parks JK, Swerdlow RH, Parker WD Jr., Bennett JP Jr: Alzheimer's disease cybrids replicate beta-amyloid abnormalities through cell death pathways. Ann Neurol 2000, 48:148-155.

31. Ray B, Lahiri DK: Neuroinflammation in Alzheimer's disease: different molecular targets and potential therapeutic agents including curcumin Curr Opin Pharmacol 2009, 9:434-444.

32. Mayeux R: Clinical practice. Early Alzheimer's disease. N Engl J Med 2010, 362:2194-2201.

33. Gorelick PB: Role of inflammation in cognitive impairment: results of observational epidemiological studies and clinical trials. Ann N Y Acad Sci 2010, 1207:155-162.

34. Levy O, Malagelada C, Greene L: Cell death pathways in Parkinson's disease: proximal triggers, distal effectors, and final steps. Apoptosis 2009, 14:478-500.

35. Lemere CA, Masliah E: Can Alzheimer disease be prevented by amyloidbeta immunotherapy? Nat Rev Neurol 2010, 6:108-119.

36. Hock C, Konietzko U, Streffer JR, Tracy J, Signorell A, Müller-Tillmanns B, Lemke U, Henke K, Moritz E, Garcia E, Wollmer MA, Umbricht D, de Quervain DJ, Hofmann M, Maddalena A, Papassotiropoulos A, Nitsch RM: Antibodies against beta-amyloid slow cognitive decline in Alzheimer's disease. Neuron 2003, 38:547-554.

37. Holmes C, Boche D, Wilkinson D, Yadegarfar G, Hopkins V, Bayer A, Jones RW, Bullock R, Love S, Neal JW, Zotova E, Nicoll JA: Long-term effects of Abeta42 immunisation in Alzheimer's disease: follow-up of a randomised, placebocontrolled phase I trial. Lancet 2008, 372:216-223.

38. Lustbader JW, Cirilli M, Lin C, Xu HW, Takuma K, Wang N, Caspersen C, Chen X, Pollak S, Chaney M, Trinchese F, Liu S, Gunn-Moore F, Lue LF, Walker DG, Kuppusamy P, Zewier ZL, Arancio O, Stern D, Yan SS, Wu H: ABAD directly links Abeta to mitochondrial toxicity in Alzheimer's disease. Science 2004, 304:448-452

39. Yao J, Du H, Yan S, Fang F, Wang C, Lue LF, Guo L, Chen D, Stern DM, Gunn Moore FJ, Xi Chen J, Arancio O, Yan SS: Inhibition of amyloid-beta (Abeta) peptide-binding alcohol dehydrogenase-Abeta interaction reduces Abeta accumulation and improves mitochondrial function in a mouse model of Alzheimer's disease. J Neurosci 2011, 31:2313-2320.

40. Dauer W, Przedborski S: Parkinson's disease: mechanisms and models. Neuron 2003, 39:889-909

41. Forno L: Neuropathology of Parkinson's disease. J Neuropathol Exp Neurol 1996, 55:259-272

42. Schapira AH, Cooper JM, Dexter D, Clark JB, Jenner P, Marsden CD: Mitochondrial complex I deficiency in Parkinson's disease. J Neurochem 1990, 54:823-827.

43. Dexter DT, Holley AE, Flitter WD, Slater TF, Wells FR, Daniel SE, Lees AJ, Jenner $P$, Marsden CD: Increased levels of lipid hydroperoxides in the parkinsonian 
substantia nigra: an HPLC and ESR study. Mov Disord 1994, 9:92-97.

44. Alam ZI, Daniel SE, Lees AJ, Marsden DC, Jenner P, Halliwell B: A generalised increase in protein carbonyls in the brain in Parkinson's but not incidental Lewy body disease. J Neurochem 1997, 69:1326-1329.

45. Alam Zl, Jenner A, Daniel SE, Lees AJ, Cairns N, Marsden CD, Jenner P, Halliwell $B$ : Oxidative DNA damage in the parkinsonian brain: an apparent selective increase in 8-hydroxyguanine levels in substantia nigra. J Neurochem 1997, 69:1196-1203.

46. Miller R, James-Kracke M, Sun G, Sun A: Oxidative and inflammatory pathways in Parkinson's disease. Neurochem Res 2009, 34:55-65.

47. Davis GC, Williams AC, Markey SP, Ebert MH, Caine ED, Reichert CM, Kopin IJ: Chronic Parkinsonism secondary to intravenous injection of meperidine analogues. Psychiatry Res 1979, 1:249-254

48. Sherer TB, Betarbet R, Testa CM, Seo BB, Richardson JR, Kim JH, Miller GW, Yagi T, Matsuno-Yagi A, Greenamyre JT: Mechanism of toxicity in rotenone models of Parkinson's disease. J Neurosci 2003, 23:10756-10764.

49. Clark IE, Dodson MW, Jiang C, Cao JH, Huh JR, Seol JH, Yoo SJ, Hay BA, Guo M: Drosophila pink1 is required for mitochondrial function and interacts genetically with parkin. Nature 2006, 441:1162-1166.

50. Poole AC, Thomas RE, Andrews LA, McBride HM, Whitworth AJ, Pallanck LJ: The PINK1/Parkin pathway regulates mitochondrial morphology. Proc Natl Acad SciU S A 2008, 105:1638-1643.

51. Yang Y, Gehrke S, Imai Y, Huang Z, Ouyang Y, Wang JW, Yang L, Beal MF, Voge $H$, Lu B: Mitochondrial pathology and muscle and dopaminergic neuron degeneration caused by inactivation of Drosophila Pink1 is rescued by Parkin. Proc Natl Acad Sci U S A 2006, 103:10793-10798.

52. Whitworth AJ, Theodore DA, Greene JC, Benes H, Wes PD, Pallanck LJ: Increased glutathione $\mathrm{S}$-transferase activity rescues dopaminergic neuron loss in a Drosophila model of Parkinson's disease. Proc Natl Acad Sci U S A 2005, 102:8024-8029.

53. Salawu F, Olokoba A, Danburam A: Current management of Parkinson's disease. Ann Afr Med 2010, 9:55-61.

54. Yuan H, Zhang ZW, Liang LW, Shen Q, Wang XD, Ren SM, Ma HJ, Jiao SJ, Liu P: Treatment strategies for Parkinson's disease. Neurosci Bull 2010, 26:66-76

55. Cardoso S, Moreira P, Agostinho P, Pereira C, Oliveira C: Neurodegenerative pathways in Parkinson's disease: therapeutic strategies. Curr Drug Targets CNS Neurol Disord 2005, 4:405-419.

56. Fahn S, Oakes D, Shoulson I, Kieburtz K, Rudolph A, Lang A, Olanow CW, Tanner C, Marek K; Parkinson Study Group: Levodopa and the progression of Parkinson's disease. N Engl J Med 2004, 351:2498-2508.

57. Kones R: Parkinson's disease: mitochondrial molecular pathology, inflammation, statins, and therapeutic neuroprotective nutrition. Nutr Clin Pract 2010, 25:371-389

58. NINDS NET-PD Investigators: A randomized, double-blind, futility clinical trial of creatine and minocycline in early Parkinson disease. Neurology 2006, 66:664-671.

59. Shults CW, Oakes D, Kieburtz K, Beal MF, Haas R, Plumb S, Juncos IL, Nutt J, Shoulson I, Carter J, Kompoliti K, Perlmutter JS, Reich S, Stern M, Watts RL, Kurlan R, Molho E, Harrison M, Lew M; Parkinson Study Group: Effects of coenzyme Q10 in early Parkinson disease: evidence of slowing of the functional decline. Arch Neurol 2002, 59:1541-1550.

60. Chen $\mathrm{H}$, Chan DC: Emerging functions of mammalian mitochondrial fusion and fission. Hum Mol Genet 2005, 14 Spec No. 2:R283-289.

61. Verstreken P, Ly CV, Venken KJ, Koh TW, Zhou Y, Bellen HJ: Synaptic mitochondria are critical for mobilization of reserve pool vesicles at Drosophila neuromuscular junctions. Neuron 2005, 47:365-378.

62. Stokin GB, Lillo C, Falzone TL, Brusch RG, Rockenstein E, Mount SL, Raman R, Davies P, Masliah E, Williams DS, Goldstein LS: Axonopathy and transport deficits early in the pathogenesis of Alzheimer's disease. Science 2005, 307:1282-1288.

63. Twig G, Shirihai OS: The interplay between mitochondrial dynamics and mitophagy. Antioxid Redox Signal 2011, 14:1939-1951.

doi:10.1186/alzrt83

Cite this article as: Hoekstra JG, et al:: Mitochondrial therapeutics in

Alzheimer's disease and Parkinson's disease. Alzheimer's Research \& Therapy 2011, 3:21. 